\title{
A perceived gap between invasive species research and stakeholder priorities
}

\author{
Helen R. Bayliss',2, Gavin B. Stewart ${ }^{3}$, Andrew Wilcox' ${ }^{1}$, Nicola P. Randall' \\ I Crop and Environment Sciences Department, Harper Adams University, Newport, Shropshire, TF10 8NB, \\ UK 2 Current address: Centre for Environmental Policy, Imperial College London, South Kensington Campus, \\ London, SW7 2AZ, UK 3 Centre for Reviews and Dissemination, University of York, York, YO10 5DD, UK
}

Corresponding author: Helen R. Bayliss (helenrbayliss@gmail.com)

Academic editor: IngolfKühn | Received 21 February 2013 | Accepted 24 August 2013 | Published 11 October 2013

Citation: Bayliss HR, Stewart GB, Wilcox A, Randall NP (2013) A perceived gap between invasive species research and stakeholder priorities. NeoBiota 19: 67-82. doi: 10.3897/neobiota.19.4897

\begin{abstract}
Information from research has an important role to play in shaping policy and management responses to biological invasions but concern has been raised that research focuses more on furthering knowledge than on delivering practical solutions. We collated 449 priority areas for science and management from 160 stakeholders including practitioners, researchers and policy makers or advisors working with invasive species, and then compared them to the topics of 789 papers published in eight journals over the same time period (2009-2010). Whilst research papers addressed most of the priority areas identified by stakeholders, there was a difference in geographic and biological scales between the two, with individual studies addressing multiple priority areas but focusing on specific species and locations. We hypothesise that this difference in focal scales, combined with a lack of literature relating directly to management, contributes to the perception that invasive species research is not sufficiently geared towards delivering practical solutions. By emphasising the practical applications of applied research, and ensuring that pure research is translated or synthesised so that the implications are better understood, both the management of invasive species and the theoretical science of invasion biology can be enhanced.
\end{abstract}

\section{Keywords}

Alien species, biological invasions, knowledge transfer, research evaluation, science policy

Copyright Helen R. Bayliss et al. This is an open access article distributed under the terms of the Creative Commons Attribution License 3.0 (CC-BY), which permits unrestricted use, distribution, and reproduction in any medium, provided the original author and source are credited. 


\section{Introduction}

Access to scientific information is important in ensuring an effective response to biological invasions (Browne et al. 2009, Simpson et al. 2009). This scientific information needs to be used judiciously alongside legislative and socio-economic information and local knowledge to inform decision-making (Segan et al. 2011). The scientific information generated through research activities can be broadly described as relating to the processes, impacts or management of invasive species (Kueffer and Hirsch-Hadom 2008). This information is continuously being published in both books and journals (Simberloff 2004, Richardson and Pyšek 2008), with the number of journal articles relating to biological invasions rising exponentially (Kühn et al. 2011). Whilst many journals in the fields of ecology and conservation biology publish papers on invasive species, the recent growth in the number of journals focusing specifically on biological invasions reflects the increasing demand in this area (e.g. Aquatic Invasions, Biological Invasions, Management of Biological Invasions, NeoBiota). Yet, despite the accumulation of a massive body of literature, there are still gaps in our fundamental knowledge about many invasive species (McGeoch et al. 2010). There is a need for much basic data on invasive species drawn from empirical research, which could be used to underpin theoretic ecological approaches, for example risk assessment (Andersen et al. 2004). Topics still to be explored fully relate to the underlying mechanisms, consequences, assessment, management, ecology and economics of biological invasions (Kühn et al. 2011, Williamson et al. 2011).

The IUCN Red List database implicates invasive species in the extinction of more than half of the 170 species for which data are available (Blackburn et al. 2010). To halt or reduce future global biodiversity loss, increased investment in the management of invasive species will be required (McGeoch et al. 2010). However, criticism has been made that much of the scientific literature on invasive species focuses on furthering knowledge and quantifying impacts rather than on delivering practical solutions (Hulme 2006, Esler et al. 2010). To explore this, we collated key priorities for invasive species science and management from stakeholders working with invasive species and then compared them to the topics of articles published over the same period in eight journals to determine whether the topics identified as important by stakeholders were being addressed by research, and to identify any areas that may require a greater focus in the future.

\section{Methods}

We gathered priorities for science and management from members of the international invasive species community using a combination of methods to increase participation. Hard-copy questionnaires designed to assess information use by invasive species stakeholders were distributed at two events in Great Britain; the GB Non-Native Species Secretariat Stakeholder Forum 2009 and the British Ecological Society Invasive Species Group Conference 2009. Questionnaires were anonymous, but respondents 
were asked to identify their main area of responsibility (i.e. research, policy, practice, others). The questionnaires finished with a question asking respondents to identify their three top priorities for invasive species science and management. The same question was distributed to delegates attending a dedicated workshop held at the European Congress of Conservation Biology in Prague, 2009. In 2010, the question was included in an anonymous electronic questionnaire exploring information selection and sharing that was distributed to the international invasive species community using the Aliens-L email list of the Invasive Species Specialist Group of the IUCN Species Survival Commission and subsequently reposted onto other web pages and email lists by recipients. Responses from the questionnaires and the workshop were entered into a spread sheet for thematic analysis, whereby related priorities were grouped using an iterative process (see online Appendix I: Stakeholder priorities for the data used in the analyses). Priorities were also analysed by comparing responses between stakeholder groups, with the eight most frequently identified priorities (those identified a total of twenty or more times) charted to allow comparison by stakeholder group.

We then undertook a search of eight journals likely to publish research of broad relevance to invasion biology. Four journals were 'traditional' ecological journals; Biological Invasions; Diversity and Distributions; the Journal of Applied Ecology; and Trends in Ecology and Evolution. The other four were subsequently selected to broaden the scope of the study, and included Ecological Economics, Journal of Environmental Management, Weed Research and Conservation Evidence. Other relevant journals which did not cover the time period of 2009-2010 (such as Management of Biological Invasions or NeoBiota, which produced their first issues in 2010 and 2011 respectively) or those which were specific to a particular group or biome (such as Aquatic Invasions) were not included. We collected all articles relating to biological invasions that were published in the eight journals during 2009 and 2010 (the same period as the priorities were gathered) except letters to the editors, obituaries, book reviews and errata, which were not included in the assessment. Papers were classified using the main theme described in the title, or using the abstract when this was not clear. We attempted to classify all of the articles against the same thematic groups that had been identified from the priorities, but as many papers related to more than one priority area or covered different topics, the thematic groups were revised using an iterative process to better reflect the nature of the articles collected. Each paper was classified against only one main topic area (see onlineAppendix II: Journal article classifications for the data used in these analyses).

The priorities and research topics were compared using odds ratios (Bland and Altman 2000), and $95 \%$ confidence intervals, $\mathrm{z}$ statistics and $\mathrm{p}$ values were calculated. Odds ratios were calculated using the formula OR = (a)/(449-a) / (b)/(789-b) whereby $a=$ the number of times a priority is identified and $b=$ the number of journal articles classified under that topic. An odds ratio of one suggests that the likelihood of the event occurring (in this case, of the topic being identified) is the same in both groups. Odds ratios were used here as the total number of priorities differed from the total number of articles retrieved. 


\section{Results}

\section{Stakeholder priorities}

197 individuals responded to the different questionnaires (Table 1). Of these, 159 respondents provided a total of 449 individual priorities. Respondents represented a range of stakeholder groups; the main being researchers ( $40.5 \%$ of respondents providing priorities), practitioners $(24.0 \%)$, and policy makers and advisors (20.3\%). Respondents from other stakeholder groups such as volunteers or knowledge brokers accounted for $15.2 \%$ of respondents.

Nineteen broad priority categories or topics were identified (Figure 1). A quarter of all of the priorities identified by stakeholders $(25.2 \%)$ related to the management of biological invasions. A further $16 \%$ related to information sharing, communication and collaboration, 9.1\% related to education and awareness raising, $6.2 \%$ to economics, $5.1 \%$ to climate change and $4.9 \%$ each to impacts of invasive species and to synergies with climate change and other threat drivers.

When compared across stakeholder groups, the two most frequently identified priorities were the same for stakeholders working in management, policy and research; these were the management of invasive species, followed by information sharing, communication and collaboration (Figure 2). Despite being the most frequently identified, these topics represented varying proportions of the overall priorities within different stakeholder categories, representing $31.2 \%$ and $15.9 \%$ of manager priorities, $38.3 \%$ and $11.7 \%$ of policy stakeholder priorities and only $18.6 \%$ and $14.1 \%$ of researcher priorities respectively (Table 2). The order and relative proportions of subsequent priorities varied between stakeholder groups. Researchers identified priorities within each of the 19 topic areas, managers within 16, policy stakeholders within 15, whilst the 'other stakeholders' category only identified priorities within 13 of the topic areas. The 'other stakeholders' group most frequently identified information sharing, communication and collaboration as a key priority (27.5\%), followed by education and awareness raising and the management of invasive species (17.4\% each).

Table I. The number and type of respondents each providing up to three priorities for invasive species science and management through questionnaires deployed at two events in 2009 and electronically in 2010.

\begin{tabular}{c|c|c|c|c}
\hline Source & $\begin{array}{c}\text { GB hard-copy } \\
\text { questionnaires, 2009 }\end{array}$ & $\begin{array}{c}\text { Workshop at ECCB } \\
\text { Conference, Prague, 2009 }\end{array}$ & $\begin{array}{c}\text { International } \\
\text { electronic questio- } \\
\text { nnaire, 2010 }\end{array}$ & Total \\
\hline Total no. respondents & 41 & 18 & 138 & 197 \\
\hline No. providing priorities & 37 & 17 & 104 & 158 \\
\hline No. working in research & 9 & 14 & 41 & 64 \\
\hline No. working in practice & 15 & 0 & 23 & 38 \\
\hline No. working in policy & 11 & 3 & 18 & 32 \\
\hline No. of other stakeholders & 2 & 0 & 22 & 24 \\
\hline Total priorities supplied: & $\mathbf{9 8}$ & $\mathbf{4 8}$ & $\mathbf{3 0 3}$ & $\mathbf{4 4 9}$ \\
\hline
\end{tabular}




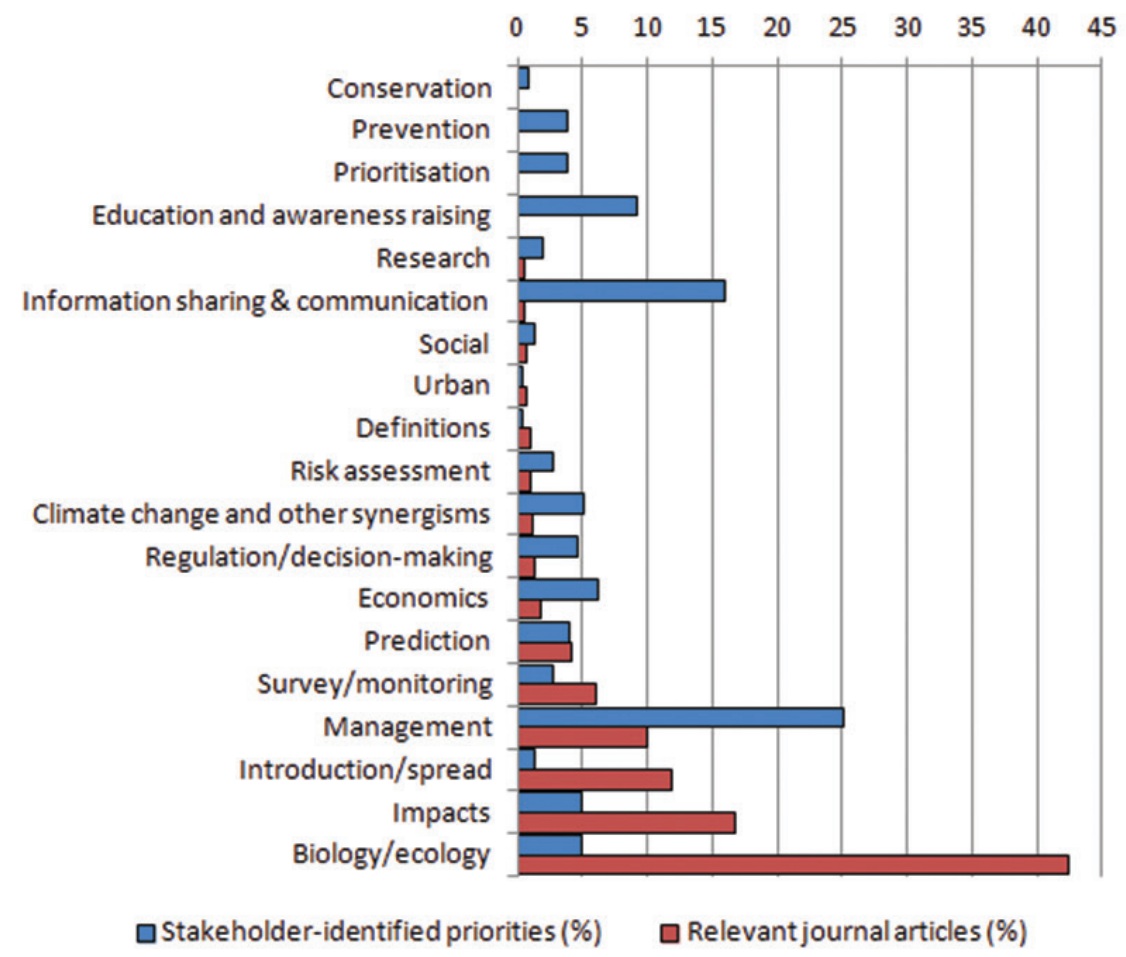

Figure I. The relative proportions (\%) of topics identified by stakeholders working with invasive species as priority areas for invasive species science and management compared to the topics of relevant journal articles published in eight journals over the same period (2009-2010).

\section{Journal articles}

789 articles of broad relevance to invasive species were identified from the eight journals during the two year period. Biological Invasions unsurprisingly published the highest number of articles deemed relevant to invasion biology as the only specialist journal included in the sample (545 articles). Diversity and Distributions published the second highest number (82), followed by Weed Research (75) and The Journal of Applied Ecology (48). Ecological Economics contained 12 articles, Journal of Environmental Management contained 11, Trends in Ecology and Evolution contained nine, and Conservation Evidence contained seven relevant articles. The majority of articles retrieved were original research articles.

Most journal articles related to the ecology or biology of invasive species (42.5\%), the impacts of biological invasions (16.7\%), or modes of introduction and spread (11.9\%). The 79 management articles identified represented $10 \%$ of the sample. Approximately $6 \%$ of papers related to surveying or monitoring and $4.2 \%$ to prediction for invasive species. All other topics were the focus of less than $2 \%$ of articles in the sample. 


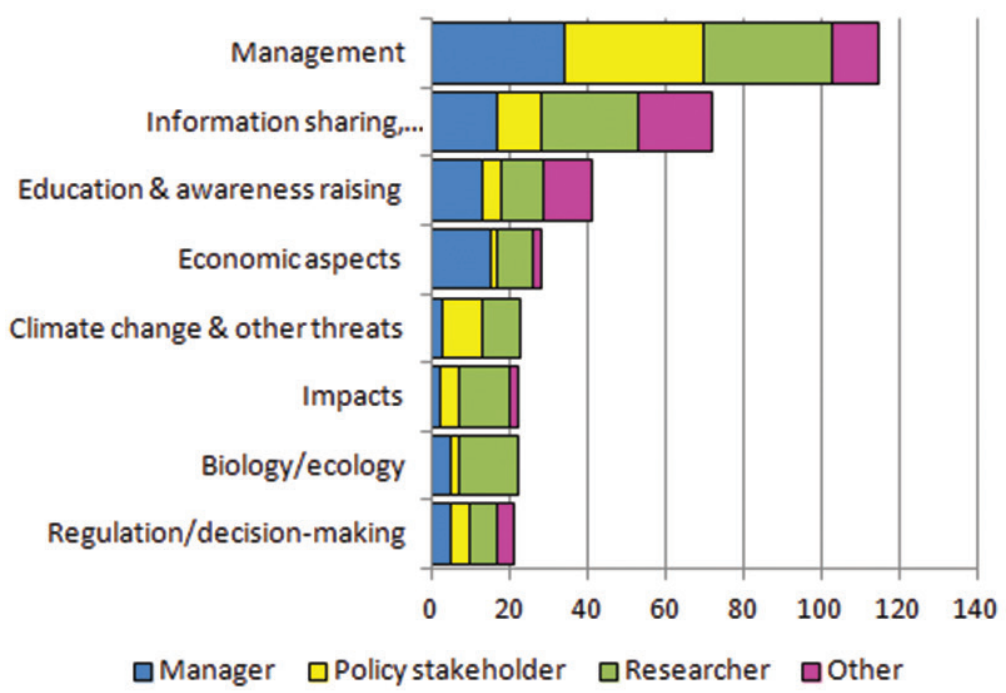

Figure 2. The eight main priority areas for invasive species science and management (each proposed twenty or more times) based on 344 of the 449 priorities identified by 158 stakeholders working with invasive species during 2009-2010 and depicted as absolute values broken down by stakeholder group. Detailed legend: Data plotted represents 94 of the total priorities provided by the 38 practitioners; 76 provided by the 32 policy stakeholders; 123 provided by the 64 researchers; and 51 provided by the 24 other stakeholders.

\section{Comparison of topics}

The greatest proportion of research papers related broadly to the biology and ecology of invasive species, whereas the greatest proportion of stakeholder priorities related to management (Figure 2). The odds ratio tests indicated that the proportion of topics identified as priorities by stakeholders were statistically different from the topics covered by journal articles for 14 out of 19 topics ( $\mathrm{p} \leq 0.05$; Table 3 ), indicating a mismatch. Education and awareness raising, prevention, prioritisation, information sharing and communication and conservation had the largest effect sizes, suggesting that they were under-represented in the literature when compared to the stakeholder priorities. Conservation, definitions, predictions, social issues and urban invasives were not significantly different with the $95 \%$ confidence interval crossing 1 , suggesting that coverage of these topics by journals is roughly proportional to their identification as priorities; however, these topics represented only small values in both categories and so the odds ratios were likely to be closer to one.

\section{Discussion}

Our results showed an apparent mismatch between the topics relating to invasive species reported in journal articles and the priority areas for science and management 


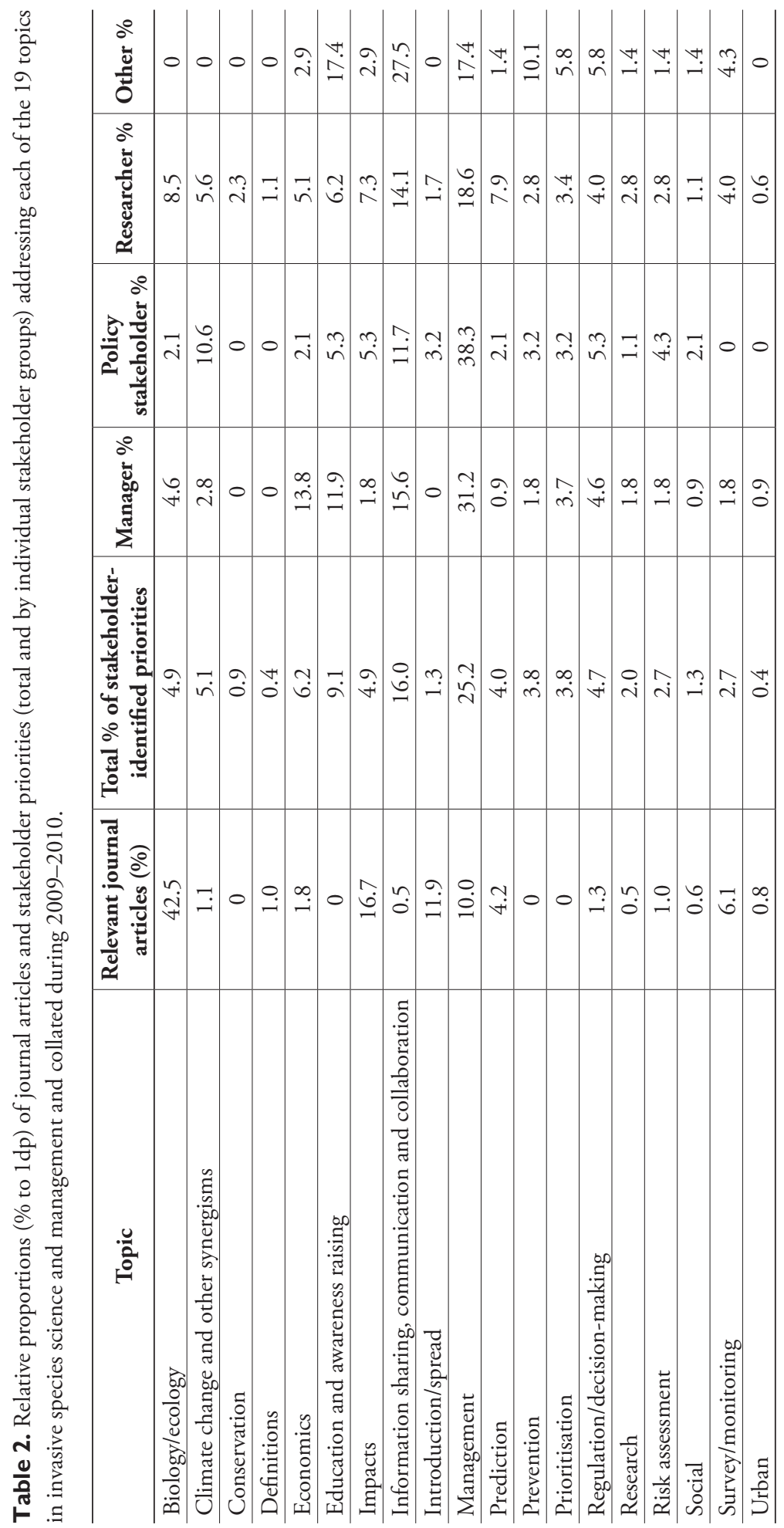




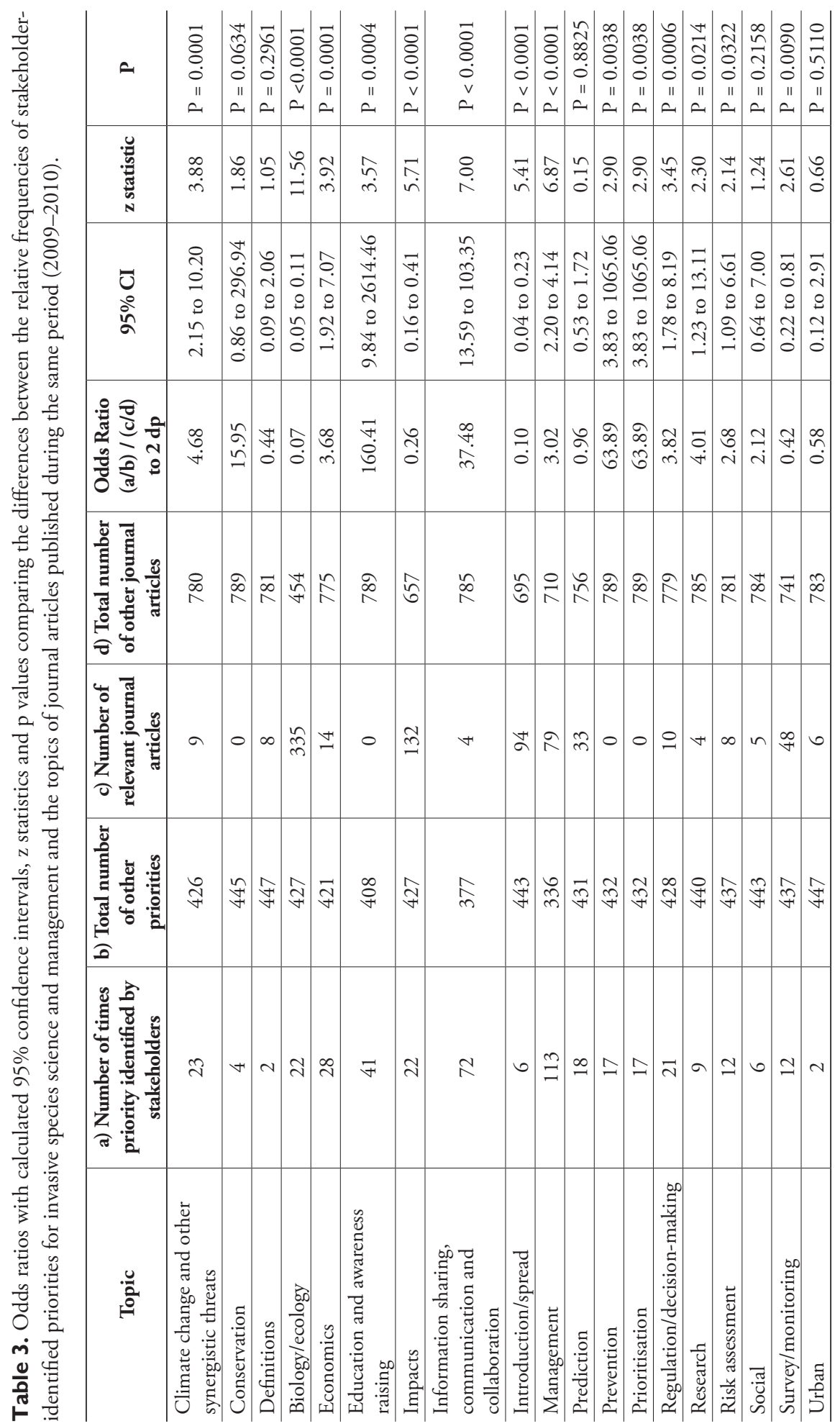


identified by stakeholders. This disparity, and in particular the lack of focus on management in the scientific literature, may be creating the perception that there is a gap between invasive species research and practice, supporting criticisms that research is not geared towards delivering practical solutions (e.g. Hulme 2006, Esler et al. 2010). However, there are several factors likely to influence this perceived mismatch.

Firstly, individual journal articles appeared to address multiple priority areas but were focused on specific species, sites or geographic regions, such as the introduction, spread and impacts of an individual species, whereas the priority areas identified by stakeholders in our sample were focused on defined topics such as 'management techniques' or 'surveying and monitoring'. This difference is likely to be due, at least in part, to the practicalities of undertaking field or laboratory research, necessitating greater focus and control. Baskerville (1997) identifies that scientists do not work or publish on the scale that ecological managers work in due to the focus on precision, and that the small temporal and spatial scales traditionally presented in the scientific literature have no context in management problems at the scales at which a manager must face. However, the increasing number of macro-ecological studies on invasive species may help to address this. Also, the stakeholders in our sample were not given a specific focus to consider when developing their priorities; the responses may have been more specific if we had asked for example about the priorities for their job, region or species of concern. Still, the information in journal articles may need to be unpacked and reassembled to better inform or address specific priorities.

Secondly, there is a clear justification for the focus on basic research on the ecology and population biology of invasive species. Fundamental research relating to both biology and management practices, as well as more advanced applied research such as modelling, are necessary to tackle the problems associated with invasive species and deliver practical solutions in the field (Simberloff et al. 2005; Van Acker 2009). Research into the population biology of invasive species is important in the management of established species and for policy formulation, but may be less useful when managing recently introduced species (Simberloff 2003). Despite the need for information on ecology and population biology to inform management, this is still lacking for many species (Simberloff 2003; McGeoch et al. 2010), with much research focused on a limited number of the most harmful species (Pyšek et al. 2008). Therefore a lack of information on the biology of a species is likely to constrain research into their management, but this may be naturally addressed as the field of invasion biology matures.

Thirdly, many journals focus on publishing articles that demonstrate novelty and broad interest, meaning that localised management studies may be seen as parochial and be rejected. Management actions are usually undertaken by non-research scientists and so the imperative to publish in academic journals is likely to be less, whilst negative results observed in the field may be difficult to get published but can have important implications for management (Sutherland et al. 2013). Other types of bias have been identified in ecological publishing that may affect the distribution of topics in the scientific literature, such as a bias towards the prevalent paradigms (Koricheva 2003). The inclusion of Conservation Evidence in this study aimed to capture articles relating 
to invasive species management submitted by practitioner-led groups that may not be typically published in most scientific journals, although the number of papers relating to invasive species published during the study time period was low.

Finally, there may be a potential lag time between the identification of a priority and the reporting of research outcomes due to the time taken to mobilise funding and undertake the research. A comparison of stakeholder priorities collated several years prior to research outputs may provide a better reflection of the responsive nature of research.

\section{Information for invasive species management}

Biological invasions are by their nature multidisciplinary, and a wide range of subjects need to contribute to their successful management (Kühn et al. 2011, Williamson et al. 2011). For example, it may be important to understand human behaviours and motivations when trying to prevent releases of potentially invasive species by the public as part of a wider management programme. These forms of socially-derived data can be explicitly integrated into decision tools to guide invasive species management (Maguire 2004), although this approach has yet to be widely implemented. The need for research into biological invasions that crosses disciplinary boundaries has been identified elsewhere (e.g. Matzek et al. 2013). However, ecological journals cannot be expected to cover all of these topics as they have a clear purpose and audience, highlighting the crucial role for invasion-specific journals in helping to bring this information together. Whilst these topics may currently receive coverage in other discipline-specific journals that provide a more appropriate fit in terms of their scope, the journals may not be easily accessible to environmental workers with limited access to published research. There may also be lower awareness of papers published in other disciplines meaning that they are not identified or used by those that would benefit from the information they contain. Information sharing via colleague recommendation and sign-posting of relevant materials, as occurs through the IUCN SSC Invasive Species Specialist Group email list for example, may help to ensure that those working in the field become aware of other relevant materials (Bayliss et al. 2012). Information sharing was frequently identified as important by stakeholders, but this may have been influenced by the mechanisms used to capture to capture the data, as many of the responses came from an information sharing questionnaire, potentially introducing bias in the responses, and should be taken into account when interpreting the results. However, the information sharing category also included collaboration and cooperative working, which may also help to explain why it was so prominent as it may have included more than one priority from each individual.

Despite differences in the cultures and activities of different stakeholder groups, the two most frequently identified priority areas were the same for researchers, practitioners and policy stakeholders. This suggests that these areas, effective management and enhanced information sharing, communication and collaboration, require urgent attention. Although many of the stakeholder-identified priorities were addressed by research papers, important topics like education and awareness raising or prioritisa- 
tion do not appear to be receiving sufficient coverage. Whilst these may not be the predominant tasks for scientists, an increasing focus on interdisciplinary projects like the Working for Water programme in South Africa may help to address the lack of coverage these topics currently receive. Although the largest proportion of respondents were researchers, their priorities still did not match the topics covered by journal articles, although they appear least different. However, they were the only stakeholders to identify as priorities some of the topics that were not significantly different from the topics of journal articles (i.e. conservation and definitions).

Although the management of invasive species was a key priority identified by stakeholders, we identified a lack of papers in the literature focused on the management of biological invasions, with most of those identified studying the impacts of invasive species control or eradication rather than its effectiveness. Other papers addressed management indirectly, for example by discussing the potential implications of a species' ecology on the effectiveness of management. The strong focus towards biology and ecology identified within the journal articles is likely to reflect the interests of the journals covered by this exercise; it is worth noting that the ecological journals contributed almost $87 \%$ of the total studies included in the analysis, and so despite efforts to include data from other journals to reduce the bias towards ecological studies, the greater volume of papers produced in these journals may also help to explain the focus towards ecological studies in the results. It may be interesting to repeat this exercise once more of the journals focused specifically on the field of biological invasions have had time to establish and mature.

\section{Next steps}

Kühn et al. (2011) identify seven broad areas in which our understanding relating to the management of invasive species could be improved. These include: social and political aspects of invasions; vector management for prevention; ballast water management; restoration; prevention tools e.g. risk analysis; legal measures; and rapid practical implementation of advances for prevention, eradication and control. We add that the sharing of experience of invasive species management, whether effective or otherwise, is important in providing an evidence base to evaluate and to inform practice. A greater focus on making management data available is required to provide the evidence needed to inform effective prevention and control. Any management data collected needs to be of a sufficient quality to allow robust analysis (Blossey 1999). In addition, we need to develop methods to analyse available management options. For example, an approach for analysing the costs and benefits of phytosanitary measures for use against quarantine pests (Kehlenbeck et al. 2012) could potentially be developed to analyse invasive species management actions more broadly.

Invasion biology as a discipline may need to find alternative mechanisms for collecting management information. There are many mechanisms available which can help, including publicly accessible newsletters and databases such as the Conservation 
Evidence database and practitioner journal (www.conservationevidence.com), which includes case studies of invasive species management projects. Hoffman et al. (2011) used the Aliens newsletter of the IUCN Invasive Species Specialist Group to detail all of the unpublished ant eradications they are aware of and include them in a synthesis of eradication attempts. However, scientists are also increasingly developing novel ways of disseminating their research findings to stakeholders. For example, attempts are being made to develop an early warning system for invasive species similar to those used in the European Union for animal health and food safety.

Of course, it is important to note that scientific information derived from research forms only one component of environmental management decisions. Previous research suggests that scientists are not keen to make decisive statements, preferring instead to articulate uncertainty and recommend other sources of information, whilst managers often have to make rapid decisions before all scientific information has been evaluated (Lach et al. 2003). Yet much of the information embedded in ecologically-focused research publications may be what is needed to inform policy and management but is incomprehensible in its current form, and may need collating and interpreting. The perceived gap between invasion biology research and practice may be best addressed through collaborative working and the translation of research findings into information accessible to end users. Scientists have a duty, particularly when their work is publically funded, to ensure that the scientific information they produce is not just published in journal articles but is explained to help resolve important policy questions (Lackey 2007). It may be that this is not a role for the scientists themselves, rather for specially trained knowledge facilitators (e.g. after Francis and Goodman 2010). Funders also have an important role in ensuring that applied research really is applied. Effective engagement is necessary to ensure that research is contextualised (Esler et al. 2010), whilst synthesis methods such as meta-analysis may help to address the difference in focal scales by combining data from multiple studies to inform decision making (Stewart 2010). Recent initiatives to collate primary research data to inform environmental management more broadly have advocated the use of synthesis methods such as systematic reviews or maps or synopses of conservation evidence (e.g. Pullin et al. 2009; Sutherland et al. 2013), and these may prove useful tools for invasive species management information.

Invasion biology, and ecology as a whole, may benefit from an independent organisation that draws scientific data together with other forms of relevant information to provide guidance on best practice, which could identify and steer funding towards the most pressing and topical questions. This would prove challenging as cohesion between stakeholders would be necessary, and this would depend on adopting a realistic and practical scale at which to operate. There is still a clear need for more basic research in invasion biology to provide the information necessary to elaborate more applied recommendations. Regardless of whether the priorities identified by stakeholders are addressed by research activities, there is a need to evaluate and share best practice. Traditional ecologically focused journals may not always provide the best forum for this, but as a community we need to ensure that information is being shared to enhance the integrated management of biological invasions. 


\section{Conclusions}

Similarities in the priorities most frequently identified by different stakeholder groups suggest that there are broad topics that urgently need addressing, particularly in relation to the lack of research directly relevant to management or to sociological aspects of invasion biology such as education and awareness-raising. These may need to be addressed through research or through the evaluation and sharing of current experience to inform future practice. Whilst there are many topics still to be explored fully in invasion biology (e.g. Kühn et al. 2011, Williamson et al. 2011) that would benefit from new research, we consider that better use of existing information, much of which is not currently optimised to address pressing issues, would provide a sound basis for future research and management to build on.

As a community, we need to ensure that any research with practical applications to invasive species management addresses the needs of the stakeholders that ultimately stand to benefit from our science, either directly by undertaking targeted research with practical applications, or by ensuring that 'pure' biological and ecological research is translated or synthesised, either by researchers or by people trained for this purpose, so that the implications are better understood. By ensuring that the potential application of research is clearly expressed, and by finding ways to bridge the difference between research papers and stakeholder needs, efforts to control invasive species and the theoretical science of invasion biology will both be strengthened.

\section{Acknowledgements}

We particularly thank all of the individuals that provided us with their priorities for science and management. We also thank the British Ecological Society Invasive Species Group, the GB Non Native Species Secretariat, the Society for Conservation Biology European Section and the other individuals and organisations that kindly supported our workshops and questionnaires. We also thank Peter Mills and Jane Hill for feedback, and Ingolf Kühn and two anonymous referees whose comments helped greatly improve an earlier version of this manuscript.

\section{References}

Andersen MC, Adams H, Hope B, Powell M (2004) Risk analysis for invasive species: general framework and research needs. Risk Analysis 24: 893-900. doi: 10.1111/j.02724332.2004.00487.x

Baskerville GL (1997) Advocacy, science, policy and life in the real world. Conservation Ecology 1: 9. http://www.consecol.org/vol1/iss1/art9/

Bayliss HR, Wilcox A, Stewart GB, Randall NP (2012) Does research information meet the needs of stakeholders? Exploring evidence selection in the global management of invasive species. Evidence \& Policy 8: 37-56. doi: 10.1332/174426412X620128 
Blackburn TM, Pettorelli N, Katzner T, Gompper ME, Mock K, Garner TWJ, Altwegg R, Redpath S, Gordon IJ (2010) Dying for conservation: eradicating invasive alien species in the face of opposition. Animal Conservation 13: 227-228. doi: 10.1111/j.14691795.2010.00372.x

Bland JM, Altman DG (2000) The odds ratio. BMJ 320: 1. doi: 10.1136/bmj.320.7247.1468

Blossey B (1999) Before, during and after: the need for long-term monitoring in invasive plant species management. Biological Invasions 1: 301-311. doi: 10.1023/A:1010084724526

Browne M, Pagad S, De Poorter M (2009) The crucial role of information exchange and research for effective responses to biological invasions. Weed Research 49: 6-18. doi: 10.1111/j.1365-3180.2008.00676.x

Esler KJ, Prozesky H, Sharma GP, McGeoch M (2010) How wide is the "knowing-doing” gap in invasion biology? Biological Invasions 12: 4065-4075. doi: 10.1007/s10530-010-9812-x

Francis RA, Goodman MK (2010) Post normal science and the art of nature conservation. Journal for Nature Conservation 18: 89-105. doi: 10.1016/j.jnc.2009.04.002

Hoffman B, Davis P, Gott K, Jennings C, Joe S, Krushelnycky P, Miller R, Webb G, Widmer M (2011) Improving ant eradications: details of more successes, a global synthesis and recommendations. Aliens 31: 16-23.

Hulme PE (2006) Beyond control: wider implications for the management of biological invasions. Journal of Applied Ecology 43: 835-847. doi: 10.1111/j.1365-2664.2006.01227.x

Kehlenbeck H, Cannon R, Breukers A, Battisti A, Leach A, Mumford J, MacLeod A (2012) A protocol for analysing the costs and benefits of phytosanitary measures. EPPO Bulletin 42(1): 81-88. doi: 10.1111/j.1365-2338.2011.02524.x

Koricheva J (2003) Non-significant results in ecology: a burden or a blessing in disguise? Oikos 102: 397-401. doi: 10.1034/j.1600-0579.2003.12353.x

Kueffer C, Hirsch Hadorn G (2008) How to achieve effectiveness in problem-oriented landscape research: the example of research on biotic invasions. Living Reviews in Landscape Research 2. www.livingreviews.org/lrlr-2008-2

Kühn I, Kowarik I, Kollmann J, Starfinger U, Bacher S, Blackburn T, Bustamante R, CelestiGrapow L, Chytrý M, Colautti R, Essl F, Foxcroft L, Gollasch S, García-Berthou E, Hierro J, Hufbauer R, Hulme P, Jarošik V, Jeschke J, Karrer G, Mack R, Molofsky J, Murray B, Nentwig W, Osborne B, Pyšek P, Rabitsch W, Rejmanek M, Roques A, Shaw R, Sol D, van Kleunen M, Vilà M, von der Lippe M, Wolfe L, Penev L (2011) Open minded and open access: introducing NeoBiota, a new peer-reviewed journal of biological invasions. NeoBiota 9: 1-11. doi: 10.3897/neobiota.9.1835

Lach D, List P, Steel B, Shindler B (2003) Advocacy and Credibility of Ecological Scientists in Resource Decision-Making: A Regional Study. Bioscience 53: 171-179. doi: 10.1641/0006-3568(2003)053[0170:AACOES]2.0.CO;2

Lackey RT (2007) Science, scientists and policy advocacy. Conservation Biology 21: 12-17. doi: $10.1111 /$ j.1523-1739.2006.00639.x

Maguire LA (2004) What can decision analysis do for invasive species management? Risk Analysis 24: 859-868. doi: 10.1111/j.0272-4332.2004.00484.x 
Matzek V, Covino J, Funk JL, Saunders M (2013) Closing the knowing-doing gap in invasive plant management: accessibility and interdisciplinarity of scientific research. Conservation Letters. Early View Article. doi: 10.1111/conl.12042

McGeoch MA, Butchart SHM, Spear D, Marais E, Kleynhans EJ, Symes A, Chanson J, Hoffman M (2010) Global indicators of biological invasion: species numbers, biodiversity impact and policy responses. Diversity \& Distributions 16: 95-108. doi: 10.1111/j.14724642.2009.00633.x

Pullin AS, Knight TM, Watkinson AR (2009) Linking reductionist science and holistic policy using systematic reviews: unpacking environmental policy questions to construct an evidence-based framework. Journal of Applied Ecology 46: 970-975. doi: 10.1111/j.13652664.2009.01704.x

Pyšek P, Richardson DM, Pergl J, Jarošík V, Sixtová Z, Weber E (2008) Geographic and taxonomic biases in invasion ecology. Trends in Ecology \& Evolution 23: 237-244. doi: 10.1016/j.tree.2008.02.002

Richardson DM, Pyšek P (2008) Fifty years of invasion ecology-the legacy of Charles Elton. Diversity \& Distributions 14: 161-168. doi: 10.1111/j.1472-4642.2007.00464.x

Segan DB, Bottrill MC, Baxter PWJ, Possingham HP (2011) Using conservation evidence to guide management. Conservation Biology 25: 200-202. doi: 10.1111/j.15231739.2010.01582.x

Simberloff D (2003) How much information on population biology is needed to manage introduced species? Conservation Biology 17: 83-92. doi: 10.1046/j.1523-1739.2003.02028.x

Simberloff D (2004) A rising tide of species and literature: a review of some recent books on biological invasions. BioScience 54: 247-254. doi: 10.1641/0006-3568(2004)054[0247:ARTOSA]2.0.CO;2

Simberloff D, Parker IM, Windle PN (2005) Introduced species policy, management, and future research needs. Frontiers in Ecology and the Environment 3: 12-20. doi: 10.1890/1540-9295(2005)003[0012:ISPMAF]2.0.CO;2

Simpson A, Jarnevich C, Madsen J, Westbrooks R, Fournier C, Mehrhoff L, Browne M, Graham J, Sellers E (2009) Invasive species information networks: collaboration at multiple scales for prevention, early detection, and rapid response to invasive alien species. Biodiversity 10: 5-13. doi: 10.1080/14888386.2009.9712839

Stewart GB (2010) Meta-analysis in applied ecology. Biology Letters 6: 78-81. doi: 10.1098/ rsbl.2009.0546

Sutherland WJ, Mitchell R, Walsh J, Amano T, Ausden M, Beebee TJC, Bullock D, Daniels M, Deutsch J, Griffiths RA, Prior SV, Whitten T, Dicks LV (2013) Conservation practice could benefit from routine testing and publication of management outcomes. Conservation Evidence 10: 1-3. http://www.conservationevidence.com/individual-study/4019\#internal-article

Van Acker R (2009) Weed biology serves practical weed management. Weed Research 49: 1-5. doi: $10.1111 /$ j.1365-3180.2008.00656.x

Williamson M, Meyerson LA, Auge H (2011) Invasion science, ecology and economics: seeking roads not taken. NeoBiota 10: 1-5. doi: 10.3897/neobiota.10.2194 


\section{Appendix I}

Stakeholder priorities. (doi: 10.3897/neobiota.19.4897.app1) File format: Micrisoft Comma Separated Value File (csv).

Explanation note: File containing stakeholder-identified priorities for invasive species science and management along with source from which they were obtained, stakeholder category (policy maker, practitioner, researcher or other) and the classification of the priority used for analysis.

Copyright notice: This dataset is made available under the Open Database License (http://opendatacommons.org/licenses/odbl/1.0/). The Open Database License (ODbL) is a license agreement intended to allow users to freely share, modify, and use this Dataset while maintaining this same freedom for others, provided that the original source and author(s) are credited.

Citation: Bayliss HR, Stewart GB, Wilcox A, Randall NP (2013) A perceived gap between invasive species research and stakeholder priorities. NeoBiota 19: 67-82. doi: 10.3897/neobiota.19.4897 Stakeholder priorities. NeoBiota 19: 67-82. doi: 10.3897/neobiota.19.4897.app1

\section{Appendix 2}

Journal article classifications (doi: 10.3897/neobiota.19.4897.app2) File format: Comma Separated Value File (csv).

Explanation note: File containing details of journal articles relevant to biological invasions included in the analysis, source journals and the main area of classification used for analysis.

Copyright notice: This dataset is made available under the Open Database License (http://opendatacommons.org/licenses/odbl/1.0/). The Open Database License (ODbL) is a license agreement intended to allow users to freely share, modify, and use this Dataset while maintaining this same freedom for others, provided that the original source and author(s) are credited.

Citation: Bayliss HR, Stewart GB, Wilcox A, Randall NP (2013) A perceived gap between invasive species research and stakeholder priorities. NeoBiota 19: 67-82. doi: 10.3897/neobiota.19.4897 Journal article classifications. NeoBiota 19: 67-82. doi: 10.3897/neobiota.19.4897.app2 